\title{
Socio Economic Status, Dietary Pattern and Nutritional Status of Teenage Pregnant Girls belonging to Rural Areas of Vellore and Dharmapuri Districts
}

\author{
K. Bhavani ${ }^{1 *}$ and Lalitha Ramaswamy ${ }^{2}$ \\ 'Research Scholar, Department of Nutrition and Dietetics, PSG College of Arts and Science, \\ Coimbatore - 641014, India; Bhavani14pndf02@gmail.com \\ ${ }^{2}$ Associate Professor and Head, Department of Nutrition and Dietetics, PSG College of Arts and Science, \\ Coimbatore - 641014, India; Ialitharam58@gmail.com
}

\begin{abstract}
A community based descriptive and cross sectional study was designed to assess the socio economic status, dietary pattern and nutritional status of teenage pregnant girls. This study was conducted in rural areas of Vellore and Dharmapuri districts in the state of Tamil Nadu, India. Convenient sampling method was used to select 139 subjects in their third trimester of pregnancy. Subjects who had registered in Primary Health Centers, Government Hospitals and private hospitals in these areas were selected. Information pertaining to general aspects, anthropometric measurements, nutrient intake, food taboos, special foods consumed during pregnancy was collected by direct interview method using the proforma. The data so collected was statistically analyzed. The findings suggest that most of the participants belonged to low socio economic status. Nutrient intake and anthropometric measurements of the subjects were very low when compared with standards. These results indicate low potential birth outcomes in relation to maternal nutrition.
\end{abstract}

Keywords: Age at Marriage, Dietary Pattern, Food Taboos, Nutrient Intake, Nutritional Status, Socio Economic Status, Teenage Pregnant Girls

\section{Introduction}

Maternal nutrition is an important determinant of the course and outcome of pregnancy and seventy five percent of fetal growth is related to maternal nutritional status [1]. However, maternal nutritional status not only determines the state of the offspring at birth, but also the future course of its developments and health in late adult years [2]. According to NFHS 3 [3], among young women aged between $15-19$ years, 8 percent have already begun childbearing, which is half of the national average of 16 percent. Ten percent of young women in rural areas are almost twice as likely to have begun childbearing but only five percent of young women in urban areas in India.

Adolescence is a period of marked changes, a period during which the individual rapidly undergoes a series of sequential physical and mental changes that transform a small child into a young adult. The dramatic physical changes increase in height and weight, deposition and redistribution of fat, increase in lean body mass

${ }^{*}$ Author for correspondence 
and enlargement of many organs including sexual components. The changes that occur suggest an increased need for specific nutrients, mainly iron, calcium, protein energy and vitamins [4]. Achievements of optimum growth in adolescent girls is therefore, considered being of utmost importance for the betterment of child survival and development as well as the maintenance of maternal nutrition [5]. Pregnant adolescents require more calories than adults of the same height and weight. Their needs for protein and calcium are also increased because of the growth of muscle and bone. Thus they may be underweight at the onset of pregnancy. Adolescent girls frequently have been found to be inadequately nourished especially deficient in iron and calcium, thiamine and vitamin B6 [6]. A majority of adolescent girls are malnourished and anemic and they enter marriage and pregnancy in an anemic state [7]. In the light of the above, the present study was planned with the objective to assess the socio economic status, dietary habits and nutritional status of the teenage pregnant girls (TPG).

\section{Materials and Methods}

A community based descriptive and cross sectional study was designed to assess the socio economic status, dietary pattern and nutritional status of teenage pregnant girls. This study was conducted in rural areas of Vellore and Dharmapuri districts in the state of Tamil Nadu, India. Convenient sampling method was used to select 139 TPG in their third trimester of pregnancy. Subjects who had registered in Primary Health Centers, Government Hospitals and private hospitals in these areas were selected. A pilot study was conducted initially and modifications were made to finalize the proforma. Information pertaining to general aspects, food taboos, special foods consumed during pregnancy was collected by direct interview method using the proforma. Anthropometric measurements like height, weight, and the weight of the girls 24 hours after delivery were recorded using standardized methodology as recommended by World Health Organization. The data so collected was analyzed using SPSS software package.

\section{Results and Discussion}

\subsection{Personal and General Information}

\subsubsection{Age}

Out of the total TPG, $61 \%$ were 18 years old, while 18
$\%$ and $6 \%$ were 17 and 16 years old. According to ICMR (1996), 66\% of first pregnancy occurs in the teenage girls, which burdens them with extra nutrition demands.

\subsubsection{Type of Family}

$39.57 \%$ and $60.43 \%$ TPGs belonged to joint and nuclear families respectively. These findings correlate well with Sangwan et al [8] and Sriharini and Lakshmi [9]. NFHS 3 reported that in rural household structure of Tamil Nadu, $23.7 \%$ and $76.3 \%$ belonged to non-nuclear and nuclear families respectively.

\subsubsection{Age at Menarche}

A larger percentage of the girls had attained menarche at 13,14 and 15 years, while $11.5 \%$ had an early menarche at 12 years of age and one at 18 years. Several studies have shown that girls attain menarche early in affluent communities but it is delayed in poor and under nourished populations. This may prolong their growth even after nineteen years. It is at this time that some girls are married and pregnancy occurs immediately thereafter which denotes the advantage of better growth if there had been a delayed marriage. In this study the mean age of TPG at menarche was 14 years. The present study correlates with that of Subapriya and Premakumari [10]. However Narain [11] has stated the mean age at menarche to be 12 years, which is low when compared to this study. It is apparent that these girls were married soon after menarche and their reproductive life has started even before the reproductive organs are fully developed.

\subsubsection{Literacy and Educational Attainment}

It was observed that $50 \%$ of the TPG were illiterates. $17 \%, 23 \%$ and $9 \%$ had studied upto primary, secondary and higher secondary school level respectively. Despite the government enforcing that all children must have basic education, it is seen that a considerable number of them had no formal education. This could also be the reason for early marriage of girls. NFHS 3 [3] reported 22 percent of females aged 6 and above in slums have no education and 22 percent of women aged 15-49 have never attended school. According to NFHS 3, literate persons are those who have either completed at least standard six or passed a simple literacy test conducted as part of the survey. As per this measure, 69 percent of women aged 15-49 are literates in Tamil Nadu and 38.4\% of rural women population aged 6 and above had no education in Tamil Nadu. 


\subsubsection{Income and Age at Marriage}

In this study most of the TPG (94.96\%) were housewives and they had stopped working temporarily on account of pregnancy and the rest were laborers. The income level of the TPG has been divided into four categories according to the HUDCO (1997) classification. In the present study it was observed that 46.04 percent and 43.16 percent of TPG belonged to Level I and Level II.

In this study the mean age at marriage of TPG were $16.82 \pm 1.08$ years and $55 \%$ had got married as early as 17 years, thus confirming that they had got married even before the legal age of marriage (18 years) [12]. Similar study done by Sivaram et al [13] reported that the mean age at marriage of females was 18.6 in the rural areas and the proportion of females married before attaining the legal age of 18 years was higher among the rural community (36.8\%) than in the urban community (28.9\%) of North Arcot Ambedkar (Vellore) district of South India.

According to District Level Household and Facility Survey 3 (DLHS 3) [14], in India, nearly half (43\%) of women aged between 20 to 24 years are married before the age of 18 years. There has been a decline in the incidence of child marriage nationally and in nearly all states (from $54 \%$ in $1992-93$ to $43 \%$ in $2007-08$ ), but the pace of change remains slow. Child marriage is a common practice all throughout the country but it affects girls in rural areas (48\%) more than in urban regions (29\%). Disparities may also be seen across different groups. Girls from poorer households and scheduled castes and, in addition to having less education tend to marry at a younger age. Girls aged between 15-19 years are more likely (66.6\%) to experience delivery complications compared to $30-34$ year-old women (59.7\%) and neonatal, infant and child mortality rates are much higher for younger girls.

Table 1. Distribution of study subjects according to their income level and age at marriage

\begin{tabular}{|c|c|c|c|c|c|c|c|}
\hline \multirow{2}{*}{ Income level } & \multicolumn{6}{|c|}{ Age at marriage } & \multirow{2}{*}{ Percentage } \\
\hline & 13 & 14 & 15 & 16 & 17 & 18 & \\
\hline $\begin{array}{c}\text { Level I } \\
\text { Upto } 2100\end{array}$ & 1 & 1 & 7 & 8 & 31 & 16 & 46.04 \\
\hline $\begin{array}{c}\text { Level II } \\
2100-4500 \\
\end{array}$ & - & 1 & 4 & 12 & 21 & 22 & 43.17 \\
\hline $\begin{array}{c}\text { Level III } \\
4500-7500\end{array}$ & - & 1 & 2 & 5 & 2 & 3 & 9.35 \\
\hline $\begin{array}{c}\text { Level IV } \\
\text { Above } 7500 \\
\end{array}$ & - & - & 1 & - & 1 & - & 1.44 \\
\hline Total & 1 & 3 & 14 & 25 & 55 & 41 & 100 \\
\hline $\begin{array}{c}\text { Chi-Square } \\
\text { Value }\end{array}$ & & & & & & & \\
\hline
\end{tabular}

Chi-Square analysis between income level and age at marriage shown in Table 1 clearly indicates that the family income level has an influence on the age at marriage. As the income levels decrease, the age at marriage also decreases. Thus, it is clear that a large percentage of TPGs belonging to lower income groups had got married at a young age.

\section{Dietary Pattern and Nutrient Intake}

Although the majority of the TPG (89\%) belonged to non-vegetarian category, the frequency of consumption of non vegetarian foods was low, due to their low economic status. Similar results were given by Dahiya and Kapoor [15]. Religious customs also influence the frequency of consumption of non-vegetarian foods. The consumption of vegetables and fruits was poor and the diet was mainly cereal based, as also observed by Narayananan and Srivatsava [16].

Table 2. Comparison of mean nutrients intake of selected TPG with RDA

\begin{tabular}{|c|c|c|}
\hline \multirow{2}{*}{ Nutrients } & \multicolumn{2}{|c|}{ Teenage pregnant girls } \\
\cline { 2 - 3 } & Actual Intake & RDA $^{*}$ \\
\hline Energy $(\mathrm{Kcal})$ & 1291.46 & 2790 \\
\hline Protein $(\mathrm{g})$ & 35.50 & 79 \\
\hline Fat $(\mathrm{g})$ & 20.05 & 35 \\
\hline Calcium $(\mathrm{mg})$ & 437.65 & 1200 \\
\hline Iron $(\mathrm{mg})$ & 13.11 & 38 \\
\hline Vitamin A $(\mu \mathrm{g})$ & 476.98 & 800 \\
\hline Thiamine $(\mathrm{mg})$ & 1.21 & 1.2 \\
\hline Riboflavin $(\mathrm{mg})$ & 0.7 & 1.9 \\
\hline Niacin $(\mathrm{mg})$ & 10.76 & 16 \\
\hline Ascorbic acid $(\mathrm{mg})$ & 41.49 & 60 \\
\hline Vitamin B12 $(\mu \mathrm{g})$ & 1.4 & 1.2 \\
\hline
\end{tabular}

* ICMR RDA 2010

24 hour recall method was used to collect information on their dietary intake from which mean intake of selected 11 nutrients was calculated (Table 2). The mean nutrient intake of TPG was low when compared to RDA except for thiamin. Vitamin $B_{12}$ and vitamin C. Mathur [17] has stated that in a periurban background the diets were inadequate and resulted in deficit of all nutrients except ascorbic acid. Low energy consumption and poor food choices make it difficult for girls to ingest the level of nutrients needed during the growth period. 


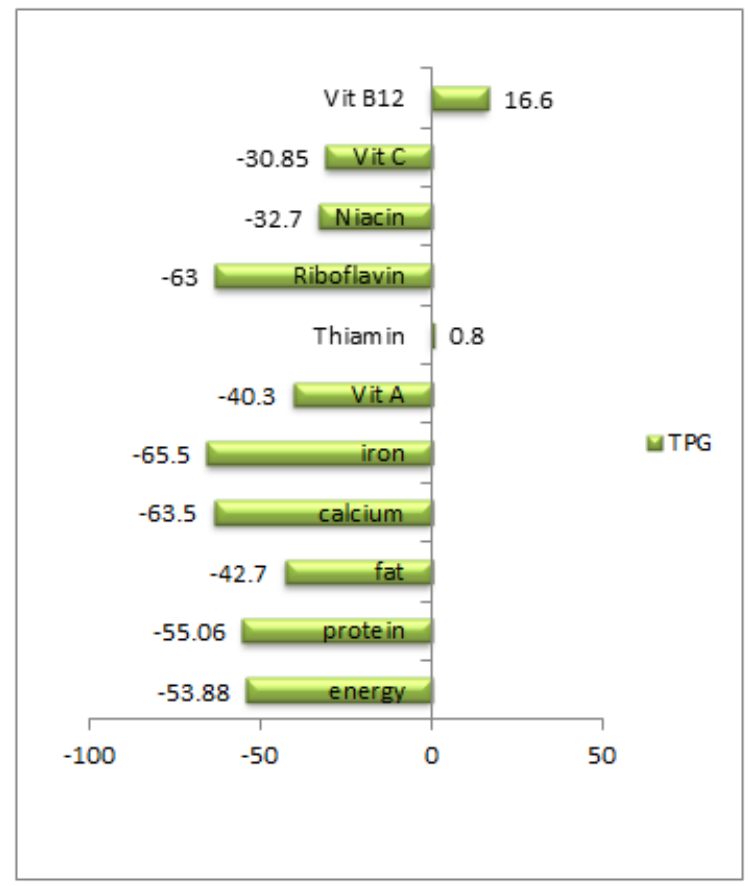

Figure 1. Percentage deficit and excess of nutrients compared with RDA of selected TPG.

A deficit in the intake (Figure 1) was observed for a majority of the nutrients except Thiamine and Vitamin B12 when compared to that of RDA. This is because a considerable percentage of the subjects belonged to low-income levels. The deficit was as high as $65.5 \%$ for iron followed by calcium (63.5\%), protein (55.06\%) and energy (53.88\%).

\subsection{Special Foods Consumed during Pregnancy}

On a daily basis ragimalt was consumed by $22.30 \%$ of TPG, dates by $24.46 \%$, and orange by $15.10 \%$. $13.67 \%$ consumed greens and $8.63 \%$ banana twice in a week while meat and fish were consumed by $13.67 \%$ and $15.10 \%$ once a week.

\subsection{Food Taboos}

Food taboos have been identified as one of the factors contributing to maternal undernutrition in pregnancy, especially in rural areas [18]. Poor maternal nutrition, especially in rural settings, adversely affects pregnancy and birth outcomes. In many local communities, pregnant women have food taboos with consequent depletion of vital nutrients. Whether rural or urban, people have their own beliefs and practices. Some are based on centuries of trial and error and have positive values while others may be useless or harmful [19]. In various studies it was seen that pregnant women in various parts of the world are forced to abstain from nutritious foods as a part of their traditional food habits [20].

In the present study the selected TPG avoided papaya (66.91\%), pineapple (46.04\%), meat (8.4\%), millet (1.8\%), egg $(6.2 \%)$, gingelly $(2.6 \%)$ and mango $(0.9 \%)$ due to food taboos like hot food, abortion and unknown reason. Jayalakshmi and Neelakanthan [21] have also stated that papaya has been avoided by majority of the subjects as it produces heat and abortion.

\subsection{Anthropometric Measurements}

The mean height deficit percent calculated for TPG (Figure 2) was significantly lower than NCHS standards in all the age groups thus confirming that the intake of nutritious foods during their growth period had been inadequate. This poor height of the girls would have definitely influenced the pre pregnancy weight. Therefore these subjects have entered pregnancy with an already deprived nutritional status.

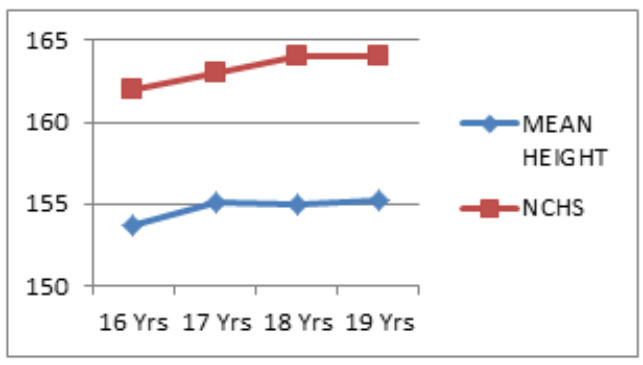

Figure 2. Mean height deficit percent calculated for TPG.

Table 3. Mean anthropometric measurements

\begin{tabular}{|c|c|}
\hline $\begin{array}{c}\text { ANTHROPOMETRIC } \\
\text { MEASUREMENTS }\end{array}$ & TEENAGE PREGNANT GIRLS \\
\hline Weight $(\mathrm{kg})$ & $45.6 \pm 4.71$ \\
\hline Height $(\mathrm{cm})$ & $155.35 \pm 6.88$ \\
\hline Body mass index & $18.64 \pm 2.47$ \\
\hline
\end{tabular}

Calorie intake takes no account of energy expenditure and it is difficult to measure calorie intake with precision. Further, effect on birth should be based on measures of extra caloric intakes during pregnancy and in which case pre pregnancy calorie intake should also be sought. In this study weight of 24 hours after delivery was used to 
calculate BMI. From Table 3, it is clear that the BMI value (18.64) was at the lower end of the normal level (18.5 -24.99) given by WHO. Naidu et al [22] have correlated BMI with birth weight and have reported least incidence of LBW infants for mothers with BMI values between 18.5 and 25. The BMI of mothers being low could result in the birth of low birth weight infants.

\section{5 . Conclusion}

In this study the TPG were from rural areas their socio economic status were low and their food intake was very low when compared to RDA. The study presents the relationship between the socio economic status and nutrient intake; it also indicates the potential birth outcomes in relation to maternal nutrition. Efforts should be taken to improve the nutritional status of TPG.

\section{References}

1. Roberts W. B., William S. R., Nutrition in pregnancy and lactation, 5th Edition. Mosby, Boston, 1993. p. 201-294.

2. Barker D. J. P., Mothers, Babies and Health in Life, 2nd Edition. Churchill Livingston, London,1998

3. NFHS 3, National Family Health Survey 3, India, Tamil Nadu, 2005-2006, International Institute For Population Sciences, Deonar Mumbai 400088, p. 27-30.

4. Manjula P., Sharada B. G. S., Rao S., Adwani M. R., Naik R., "Nutritional Status Of Adolescents In An Urban Area Of Karnataka", The Indian Journal Of Nutrition And Dietetics, vol. 32(5), p. 134-138, 1995.

5. Jondhale J. P., Reddy S. N., Vijaya M. N., "Nutritional Status of school going adolescent girls of parbhani", The Indian Journal Of Nutrition And Dietetics, vol. 38, p. 262, 2001.

6. Buckley K., Kulb W., High risk maternity nursing manual, 2nd Edition. Williams and Wilkins, Maryland, USA, 1993. p. 414-417.

7. Ghosh S., Nutrition and child care- a practical guide, Medical publisher (P) Ltd, New Delhi, 1997. p. 25-47.

8. Sangwan S., Chhikara S., Punia S., "Factors Affecting Nutritional Status", The Indian Journal Of Nutrition And Dietetics, vol. 30, p. 159-166, 1993.

9. Sriharini D., Lakshmi U.K., "Effect of Supplementation of Cynodon Dactylon (Arugampul) Juice/ Powder on Anemic Pregnant Women(20-30 years)", The Indian Journal Of Nutrition And Dietetics, vol. 38, p. 281-291, 2001.
10. Subapriya S. M., Premakumari S., "Growth profile and Hemoglobin levels of adolescent girls from affluent and low income families of urban and rural areas of Coimbatore", The Indian journal of nutrition and dietetics, vol. 30(5), p. 113-119, 2001.

11. Narain A., A comparative study of factors influencing menarchial age in rural and urban areas of coimbatore city, Current trends in biological sciences, abstracts, Avinashilingam deemed university, Coimbatore-43, 2002. p. 51.

12. Lakshmanan., Proposal to amend the prohibition of child marriage act, 2006 and other allies laws, the law commission of india, 2008 report no. 205. p. 38.

13. Sivaram M., Richard J., Rao P. S., "Early Marriage Among Rural And Urban Females Of South India”, Journal of Biosocial Science, vol. 27(3), p. 325-331, 1995.

14. DLHS 3, District Level Household and Facility Survey, 2007-08, Govt of India, International Institute for Population Sciences April 2010.

15. Dahiya S., Kapoor A. C., "Anemia In Women In A Selected Rural Area Of Haryana Effect Of Dietary Intake Level", The Indian journal of nutrition and dietetics, vol. 32(8), p. 324, 1995.

16. Narayananan, A., Srivatsava S., Nutritional Status, Physical Fitness, Health Among Rural and Urban Adolescent Girls In Coimbatore Districts, NSI XXVI Annual conference Abstracts NIN, Hyderabad, 1993.

17. Mathur, P., Rapid Assessment Procedures For Health and Nutritional Status of Adolescent Girls Form a Periurban Background, NSI XXVI annual conference abstracts, NIN, hyderabad, 1993.

18. Olurinde A. O., "Jamilu Tukur - Identifying Pregnant Women Who Would Adhere to Food Taboos in a Rural Community: A Community Based Study", African Journal of Reproductive Health, vol. 16(3), p. 72, 2012.

19. Park K., Park's Textbook of Preventive and Social Medicine, 21th Edition. Jabalpur: M/S Banarsidas Bhanot Publishers, 2011. p. 603

20. Mitchell, J., Mackerras, D., "The Traditional Humoral Food Habits Of Pregnant Vietnamese-Australian Women And Their Effect On Birth Weight", Australian Journal of Public Health. vol. 19(6), p. 629-633, 2010.

21. Jayalakshmi N., Neelakanthan S., "Study on the food habits of the rural population", The Indian journal nutrition and dietetics, vol. 32, p. 295, 1995.

22. Naidu A. N., Neela J., Rao N. P., "Maternal Body Mass Index And Birth Weight”, Nutr News, NIN, vol. 12(2), 1991. 